\title{
The duration of the school-to-work transition in Italy and in other European countries: a flexible baseline hazard interpretation
}

\author{
Francesco Pastore
}

Department of Economics, University of Campania Luigi Vanvitelli, Capua, Italy, and

Claudio Quintano and Antonella Rocca

\author{
Department of Management and Quantitative Studies, \\ University of Naples "Parthenope", Naples, Italy
}

\begin{abstract}
Purpose - The Italian school-to-work transition (STWT) is astonishingly slow and long in comparison to the other EU countries. We analyze its determinants comparing the Italian case with Austria, Poland and the UK. Design/methodology/approach - The analysis is based on a Cox survival model with proportional hazard. The smoothed hazard estimates allow us to identify the nonlinear path of the hazard function.

Findings - The authors reckon that the actual length of the transition to a stable job is around 30 months in Italy. Conversely, it is less than one year in the other countries. Women are particularly penalized, despite being on average more educated than men. Tertiary or vocational education at high secondary school strongly increases the hazard rate to a regular job. The smoothed hazard estimates suggest positive duration dependence at the beginning of the transition and slightly negative thereafter.

Practical implications - Stimulating economic growth and investing in education and training are important pre-conditions for shortening the transition.

Originality/value - Despite the duration of the STWT is one of the most important indicators to measure the efficiency of the STWT, it is not easy to measure. The authors build on their previous research work on this topic, but relaxing the assumption of a monotonic hazard rate and using the flexible baseline hazard approach to test for the existence of nonlinear duration dependence. Furthermore, they extend the analysis by including student-workers who attended a vocational path of education, in order to detect its effectiveness in allowing young people finding a job sooner.
\end{abstract}

Keywords Duration, School-to-work transition, Europe, Italy, Transition regime

Paper type Research paper

\section{Introduction}

The school-to-work transition (STWT) is the period from the end of the studies to the attainment of a regular job. Even if it represents a crucial step in the life cycle of an individual, sometimes affecting all the future career path, information about its duration and its

\section{JEL Classification - H52, I2, I24, J13, J64, J68}

(C) Francesco Pastore, Claudio Quintano and Antonella Rocca. Published by Emerald Publishing Limited. This article is published under the Creative Commons Attribution (CC BY 4.0) licence. Anyone may reproduce, distribute, translate and create derivative works of this article (for both commercial and non-commercial purposes), subject to full attribution to the original publication and authors. The full terms of this licence may be seen at http://creativecommons.org/licences/by/4.0/legalcode

A longer and more detailed version of this paper is available as an IZA discussion paper for further reference. The authors thank the associate editor Thomas Lange and the anonymous referee for very useful suggestions. However, the usual disclaimer applies.

Compliance with ethical standards: No funding was received.

Conflict of Interest: The authors declare that they have no conflict of interest.

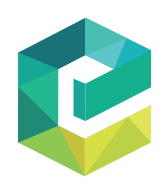

International Journal of Manpower Vol. 43 No. 7, 2022 pp. $1579-1600$ 
IJM

43,7

determinants are very few and fragmentated also because of the lack of official statistical data.

The analysis of the STWT requires first of all to investigate the ability of education systems to provide young people with higher levels of education and acquire the general and job-specific work-related competences required by perspective employers (Pastore, 2015, 2018). Moreover, the hardship related to entry is strongly linked with the characteristics of the labor market and type of transition regime, that is the mix and interactions between the education system, the labor-market and their regulating institutions.

In sequential education systems, part of the human capital, namely the work-related competences, are acquired after completing education. Any barrier in the labor market may slow down the STWT process, contributing to increase the relative disadvantage in terms of work experience as compared to adults (Pastore, 2015, 2018). Conversely, an education path strongly connected with the enterprises, such as the dual model of Continental countries makes in most of the cases the transition to work faster and smoother, with many students starting to work even before completing their studies (student-workers).

The aim of this paper is to analyze the duration of the STWT in Italy and its determinants comparing the Italian case with other European countries. The duration of the STWT is one of the most important indicators to consider when measuring its efficiency (Ryan, 2001; Raffe, 2008; Pastore, 2015, 2018; Pastore et al., 2020) and therefore should be continuously monitored, but it is not easy to compute. The few studies available have demonstrated the existence of a great variability across European countries.

By providing a new, more accurate measure of the duration of the STWT, our paper aims to contribute, first, to changing the traditional way of thinking of investment in human capital. In fact, the duration of the STWT in conditions of uncertainty may significantly affect, among others, the ex ante returns to higher education and explain the decision to enroll at or to drop out from higher secondary school or university (Altonji, 1993). The reduction in the enrolment rate, and also in the share of university graduates, is becoming a major problem in several advanced countries where the duration of the STWT is too long (see the recent editions of the "Education at a glance" reports published by the OECD). Italy is currently the OECD country with the lowest rate of tertiary education attainment (for a recent assessment, see De Angelis et al., 2016).

Providing evidence of the duration of the STWT is very important for academic research, educational institutions and policymakers at all levels. An extremely lengthy transition might change the idea that ex post returns computed only for graduates is the right indicator to consider when studying the decision to invest in higher education. Although Mincerian earnings equations have become one of the most common tools to estimate returns to education, they have been mainly based on the distorted sample of workers who have actually succeeded in graduating. However, it would be important to weigh these expost returns against the probability of attaining a degree and of finding a job in each period of time to measure ex ante returns. Decisions to invest in education may be better understood with respect to this more accurate measure, rather than with respect to the one currently used, based on the received wisdom.

In a previous research work (Pastore $e$ t al., 2020), we examined the Italian STWT duration in 2017 by focusing on macroeconomic and individual-level determinants by means of parametric survival models adopting a Weibull distribution. We found evidence of positive duration dependence, which means that the probability of finding a job increases with time from study completion. In the current paper, we innovate the analysis from different points of 
view. First, we relax the assumption of a monotonic hazard rate and update the analysis to a more recent year, 2018, the last one for which the data is available. We use the flexible baseline hazard approach, based on the Cox model, to test for the existence of duration dependence. This allows us to identify the nonlinearity pattern of hazard functions. Results highlight indeed that the hazard function increases in the first period to quickly decrease thereafter.

We provide estimates of the STWT by different levels of education and find evidence of much longer transitions for medium (high secondary school attainment) and above all low (only compulsory education attained) educated.

A further innovation consists of looking at gender differences. Women experience longer duration, despite being more educated than men; this applies even when we look only at completed transition, therefore correcting for the possible decision to remain inactive.

Third, through EU-SILC, we provide comprehensive comparable evidence on the duration of the STWT in different European regimes, each represented by a specific country: Austria for the Central-European regime; the UK for the liberal regime; Poland for the Eastern European post-communist regime and Italy for the Mediterranean regime. Scandinavian countries are not considered because their EU-SILC does not provide sufficient information to measure the duration of the STWT.

Finally, as shown in the data section, we enlarge the sample including in the econometric estimates also student-workers who attained a vocational education, in order to detect the capacity of the education system to provide job opportunities sooner than other educational tracks. We quantify the impact on the STWT of the vocational rather than general program of education. We find evidence of a very strong impact of the vocational path of education in Germany and Poland as compared to Italy.

The rest of the paper is as follows: section 2 contains a review of the literature on STWT and the related issues of its measurement; section 3 illustrates data and methodology while in section 4 we show the main findings of the study. Finally, section 5 concludes.

\section{Literature review and statistical concerns of the STWT}

At the European level, the main official statistical sources to monitor the individuals' entry in the labor market are the Labor Force Survey (LFS) and EU-SILC, but none of them allows fully to reach this goal.

In 2009, EUROSTAT (2012) tried to address the gap in the measurement of the STWT among EU countries by using the ad hoc module of European LFS "Entry of young people into the labor market" [1]. The analysis showed remarkable differences across countries, but not as remarkable as one would have expected. Southern and Eastern European countries were the slowest, but not as much as anecdotal evidence suggested. Italy was second only to Greece in terms of the duration of the transition for university graduates (nine months) and only seventh for higher secondary school graduates (13.5 months).

Probably, the way in which the Eurostat indicator of the STWT duration was constructed contributes to smooth cross-country differences. Indeed, Eurostat considered completed any transition to the "first significant job", meaning a job of at least three months and, therefore, not necessarily a permanent or even a "regular job" (we will provide the Eurostat definition of a regular job later). However, the "first significant job" may not in reality represent the end of the STWT. This generates a dramatic underestimation of the overall duration of the transition. It is a quite well-known fact, already noted in the literature, that the so-called twotier reforms and the diffusion of temporary work have often led to a decrease in the duration of unemployment spells, but not necessarily in the transition to a permanent job, i.e. the duration of the overall transition. Quintini et al. (2007, Table 1) are perhaps among the first to have reported this, with reference to Spain and Italy, among others. In the latter country, they
Duration of the STWT in Italy 
IJM

43,7

$\begin{array}{cc} & \text { Variables } \\ \text { EU-SILC } & \text { LFS }\end{array}$

Starting point of the STWT PE030: year of study completion

Ending point of the STWT PL190 (date when an individual attained the first regular job, defined as "any paid work activity that has lasted for at least six months, including temporary work, but excluding seasonal and occasional work")

Highest level of education attained

PE040: highest level of education attained and type of path, but no distinction between ISCED 5,6,7,8 for many countries

General or vocational path

No

Field of study

Finale grade No

Experience in terms of No

training or additional

Table 1.

A comparison between LFS and EU-SILC data

HATYEAR, MONTHYEAR: year and month of study completion No (variable STARTIME reports the number of years the individual has spent in the current job, without providing information on the past work experiences)

HATLEVEL: highest level of education attained

HATVOC: general/vocational HATFIELD: field of study

No

No

education received during the STWT

Territorial detail

NUTS2

estimated that the duration of the transition from education to a permanent job was 44.8 months, much longer than the Eurostat estimate; similar figures were found for Spain.

Moreover, in the last years the length of the transition is much increased, especially in Italy and other Southern European countries because of the still ongoing economic crisis.

The main, but certainly not the only reason for this long duration of the STWT is the lack, among young people, of professional skills sufficient to allow companies to hire them on a permanent basis sooner. In turn, this gap in work experience is due, first of all, to the lack of opportunities during the course of school/university, especially in countries adopting a sequential education system; second, after completing education, to a labor market where institutions are not able to provide young people with the right opportunities to acquire work related competences (Ryan, 2001; Raffe, 2008; Pastore, 2015, 2018).

When the STWT is long, this means that young individuals experience repeated failures in job search that may lead to prolonged unemployment, with long-term negative consequences on career prospects (Bell and Blanchflower, 2010) or to the exit from labor market due to discouragement. Many economists agree on the scarring effect of prolonged periods of inactivity or in failing in the job search (Arulampalam, 2001). Previous research (see among others Lancaster, 1979; Nickell, 1979) found that these experiences could act reducing the probability to reach a stable job in the future because remaining unemployed or inactive for a long period impoverishes human capital and, from the supply side, is seen by employers as a sign of scant attitude to work (Pastore et al., 2021 for a recent assessment). This phenomenon is called negative duration dependence. However, more recent research (Heckman and Borjas, 1980; Heckman and Singer, 1984) found that negative duration dependence is essentially due to omitted heterogeneity in unemployed job seekers: longer unemployment spells are related to less skilled and motivated individuals.

The time spent during the SWT and the related experiences deeply affect the individuals' whole life and therefore the countries' economic and social prospects. It influences the young adults' sense of self-efficacy about their decision-making abilities and their coping skills, the 
stability of their initial vocational choices, the speed with which they learn new job responsibilities and their level of comfort with new colleagues and workplace norms (Caroleo et al., 2020). Sometimes, this may lead individuals to accept an unqualified job, generating over-education or over-skilling or may induce them to fall in a trap of low-paying, temporary or unstable jobs. Conversely, the presence of institutions which give assistance to young people on opportunities in terms of jobs and training is crucial, especially in countries where the level of unemployment is high. Experiences in terms of training could allow young people to improve their skills and competences, therefore increasing their employability. The recent wide diffusion of temporary work, especially in some European countries has been finalized to reduce the labor market rigidity and to create job opportunities for young people, even if for a brief period of time. They can represent an opportunity to accumulate work experience, to acquire the skills required by the labor market and, in some cases, may represent an entrydoor for an open-ended contract (Korpi and Levin, 2001). However, on the other side, in too many cases, it has led to a precariousness of job positions especially for young people, contributing to ward off the achievement of a stable job.

Recent research on Italy has focused on the transition of university graduates. Caroleo and Pastore (2018) study the first 5 years of career of university graduates, by using AlmaLaurea data. They highlight important differences across fields of study and areas of residence in the probability to experience overeducation and overskilling. They test for the determinants of overeducation/overskilling and find that a human capital interpretation in terms of lack of work experience among university graduates as a factor of overeducation/overskilling cannot be rejected.

A study by Anelli (2020), which is based on linking AlmaLaurea data with data from the social security archives, allows reconstructing the first two decades of the working career of university graduates in Italy, which shows amazing differences across fields of study. He looks at the earnings of university graduates as reported to the social security by graduates. Interestingly, the study shows that some of the conclusions of Caroleo and Pastore (2018) reached for some fields of study are not confirmed in a longer perspective, which suggests that a process of learning by searching and by doing is taking place and that young graduates, especially in some fields of study, take some time to develop fully their career also from an economic point of view.

We consider these two contributions complementary to this work, in as much as they provide a focus on fields of study which is impossible to attain with the EU-SILC data, as discussed at more length in the data section.

From a theoretical point of view (Ryan, 2001; Raffe, 2008; Pastore, 2015, 2018), the STWT process is completed when the individual has gained all the components of human capital that are necessary to gain a job. But questions remain regarding which type of job. A recent International Labor Organization (ILO, 2020) publication suggests considering the transition completed when she/he has found a permanent or, if temporary, at least satisfactory, job. Indeed, if they are sufficiently satisfied with their job, they will stop searching for another one.

\section{Methodology and data}

\subsection{Data}

To measure the STWT duration requires knowing its starting and the ending points, that is when young people complete their studies and when they start their first regular job. Also important is the information about the field of studies completed, the grades achieved, the experience lived during the STWT in terms of training or additional education received and actions taken in order to find a job. Finally, as the STWT is strongly affected by the economic and social context where the individual lives, it should be important also to collect information with a sufficient territorial detail.
Duration of the STWT in Italy

1583 
IJM

43,7

1584

Unfortunately, information on several of these aspects is missing in many cases, with the exception of some LFS ad hoc modules. In Table 1 we briefly report the specific information on these topics in the LFS and EU-SILC data bank.

We use the EU-SILC cross-section version for 2018. The EU-SILC questionnaire asks respondents to provide the year when they attained the highest level of education (variable pe030) and the year when they achieved their first "regular job" (variable pl190). The latter is defined as any paid work activity (without distinguishing between self-employed and wage employees) that lasted for at least six months, excluding seasonal and occasional work. Regular work may be temporary or permanent. We focus on all young people that, at the time of completing the questionnaire were 18-34 years old, excluding from the analysis the permanently disabled, students and those in military service.

We include in the analysis the so-called student-workers, namely individuals who started their first regular job before finishing their studies. Their duration is set to zero. Different from previous research work (Pastore et al., 2020, 2021), in this paper, we include in the econometric analysis the student-workers who followed a vocational path at high secondary school. In this way, we can measure the ability of this educational track to guarantee a faster and smoother transition to work [2]. Conversely, we decided to exclude from the analysis students who start working for reasons not directly connected with school attendance. The latter do not experience at all the period of transition to work. Clearly, the inclusion of studentworkers should reduce the average duration. It is important to note that the - even if partialexclusion of student-workers from the analysis, leads to over-estimating the duration of the STWT in countries where the practice to start to work before attaining the highest level of education is more frequent, such as in Continental countries.

We then distinguish between "completed" transitions and transitions that were incomplete, meaning that they had not found a regular job at the time of the interview. For the former, the transition ends when they find a regular job. For the latter, the transition lasts from the time of study completion until the time of the interview. The latter are either actively seeking a job or are inactive.

Finally, initially, we assign the status of incomplete transition also to those individuals who found a regular job in the past, but are not employed at the time of the interview. However, as a robustness check, we remove this assumption and repeat the estimates considering completed the transition also for these individuals who found a job in the past [3].

Moreover, we distinguished individuals by gender and by education attainment: (1) compulsory or below (ISCED 0-2); (2) higher secondary (ISCED 3-4); and (4) tertiary education (ISCED 5-8) (respectively, low, medium and high education levels).

Unfortunately, our databank neither allows us detecting the type of tertiary education attained (three-year vs three-plus-two-year degree) nor the field of study (e.g. arts degrees vs STEM fields).

\subsection{Methodology}

For the identification of the determinants of the durations of the STWT, we estimated a semiparametric Cox proportional hazard model. This is quite a standard model and hence here we will provide only a short overview of its main features. The hazard rate (the instantaneous probability to find a job at any duration of the STWT) depends on a given set of covariates representing the personal characteristics of the individual in the sample, rather than the characteristics of the job held (sector of industry, type of labor contract, etc.) to avoid endogeneity problems. The main feature of this model is that it leaves its baseline hazard function $\alpha(t)$ free to vary with time, without imposing a given functional form, as in the parametric version of the model. Let $h(t)$ be the hazard function: 


$$
h_{i}(t)=h_{0}(t) \exp \left(\beta_{1} x_{i 1}+\beta_{2} x_{i 2}+\ldots \beta_{k} x_{i k}\right)
$$

where:

(1) $t$ is the survival time in the STWT;

(2) $h(t)$ is the hazard function as determined by a set of $k$ covariates $\left(x_{1}, x_{2}, \ldots, x_{k}\right)$; and

(3) $\beta_{k}$ are the relative coefficients $\left(\beta_{1}, \beta_{2}, \ldots, \beta_{k}\right)$ measuring the impact (i.e. the effect size) of covariates on the hazard rate.

The term $h_{0}$ is referred to as the baseline hazard. It corresponds to the value of the hazard if all the $x_{i}$ are null. The hazard varies over time, i.e. when $t$ changes. The Cox model function can also be written as a multiple regression of the logarithm of the hazard on the variables $x_{i}$. In this case, the baseline hazard represents the intercept term varying overtime:

$$
\log h_{i}(t)=\alpha(t)+\beta_{1} x_{i 1}+\beta_{2} x_{i 2}+\ldots \beta_{k} x_{i k}
$$

This survival model is the most appropriate when we have no prior assumptions regarding how the relative hazard changes with covariate. Indeed, the Cox proportional hazard model assumes that: (1) the ratio of the hazard function for two individuals with different sets of covariates does not depend on time; (2) time is measured on a continuous scale; (3) censoring occurs randomly (Fisher and Lin, 1999; Therneau and Grambsch, 2001). The Cox model is therefore more flexible and, unlike parametric models, does not require the estimation of the baseline hazard function. Meyer (1990) highlighted that it yields more plausible coefficients than those obtained from commonly used Weibull models. Indeed, estimation of the shape of the baseline hazard provides us with more direct information on whether there is duration dependence, whether it is positive or negative or whether it is nonlinear, namely whether it takes positive or negative slope at different durations. The baseline hazard will directly provide the shape without testing the statistical significance of any given parametric function.

We used Stata 15 for the econometric analysis. The graphical representation of the smoothed hazard functions, calculated as a weighted kernel-density estimate using the estimated hazard contributions, allows us identifying the type of duration dependence. We will have evidence of positive duration dependence if the hazard rate increases over time, which means that the probability of exiting from the STWT increases with time, supporting the theory of "learning by searching": during the permanence in the STWT, individuals increase their skills and capacity in searching for a job because they gain work experience and accumulate work-related competences. Conversely, in case of negative duration dependence, the probability of exit from the STWT decreases over time as the experience of prolonged periods out of the labor market reduces the individuals' human capital potentials and therefore their future career prospects. Another non-alternative possible interpretation for this positive duration dependence is that young individuals may reduce their reservation wage (or revise the characteristics of the "desired job") and the unemployment spell increases [4].

\section{Findings}

\subsection{Descriptive analysis}

For an overall view of the characteristics of the STWT in Austria, Italy, Poland and the UK, we report the descriptive statistics by gender and level of education on: share of studentworkers (Table 2); the mean age when individuals start their transition (Table 3); and when they complete the transition (Table 4). In Table 5 we show the share of transitions completed 
IJM

43,7

\section{6}

at the time of interview and the mean duration of the transition, both including and excluding the in-transition at the time of the interview. Finally, in Table 6 we investigate the determinants of permanence in the STWT, that is unemployment or inactivity, for those that at the time of interview are still in-transition [5].

Table 2 shows that the highest level of education attained by young people dramatically differs across countries, confirming that the performance of the STWT is closely related to the ability of the education system to keep students in education longer. In particular, in Italy, the share of tertiary-educated individuals is one of the lowest in Europe, showing also a significant gender gap. Indeed, only $15 \%$ of men attain a university degree, compared to $26 \%$ of women. In the UK, these figures are higher than $43 \%$, without significant gender differences. Conversely, the share of low-educated, i.e. young people with compulsory education only, is still sizeable in Italy: $27.85 \%$ among men and $23.92 \%$ among women. The corresponding percentages in Poland are below $10 \%$.

The share of student-workers in Italy is around $11 \%$, the lowest among the countries analyzed, while elsewhere it overcomes $40 \%$ at least among university students.

Also, the mean age when individuals complete their studies varies widely across EU countries (Table 3), especially for the tertiary educated. The mean age of entrance into the labor market for Italian tertiary graduates is 25 years and is the highest, especially when compared with the UK, where the comparable figure is 22 years. Another surprising result is the high mean age of the attainment of a low educational level, around 17 years in the UK.

\begin{tabular}{|c|c|c|c|c|}
\hline Level of education & $\%$ & $\begin{array}{l}\text { Men } \\
\% \text { student-workers }\end{array}$ & $\%$ & $\begin{array}{l}\text { Women } \\
\% \text { student-workers }\end{array}$ \\
\hline \multicolumn{5}{|l|}{ Italy } \\
\hline Compulsory or below & 27.85 & 2.47 & 23.92 & 0.94 \\
\hline Higher secondary & 57.57 & 10.23 & 50.17 & 8.41 \\
\hline Tertiary & 14.58 & 24.79 & 25.90 & 20.93 \\
\hline All & 100 & 11.88 & 100 & 10.87 \\
\hline$N$ & 2,484 & 2,484 & 2,352 & 2,352 \\
\hline \multicolumn{5}{|l|}{ Austria } \\
\hline Compulsory or below & 17.61 & 8.57 & 16.00 & 2.01 \\
\hline Higher secondary & 49.97 & 63.35 & 43.75 & 54.36 \\
\hline Tertiary & 32.42 & 52.03 & 40.25 & 44.89 \\
\hline All & 100 & 50.03 & 100 & 41.17 \\
\hline$N$ & 844 & 844 & 904 & 904 \\
\hline \multicolumn{5}{|l|}{ Poland } \\
\hline Compulsory or below & 9.84 & 2.84 & 4.36 & 0.55 \\
\hline Higher secondary & 61.59 & 16.91 & 47.99 & 11.66 \\
\hline Tertiary & 28.57 & 57.11 & 47.65 & 47.82 \\
\hline All & 100 & 27.01 & 100 & 28.41 \\
\hline$N$ & 2,076 & 2,076 & 2,084 & 2,084 \\
\hline \multicolumn{5}{|l|}{ United Kingdom } \\
\hline Compulsory or below & 17.00 & 18.64 & 9.82 & 9.07 \\
\hline Higher secondary & 39.64 & 35.68 & 39.62 & 30.86 \\
\hline Tertiary & 43.35 & 43.54 & 50.55 & 44.53 \\
\hline All & 100 & 36.19 & 100 & 35.63 \\
\hline$N$ & 1,424 & 1,424 & 1,610 & 1,610 \\
\hline \multicolumn{5}{|c|}{ Source(s): Own elaborations on EU-SILC data } \\
\hline
\end{tabular}

Table 2.

Distribution of individuals $18-34$ years old by gender and by level of education attained and share of studentworkers in selected European countries 
Table 3.

Mean age of study completion by education level and gender in selected European countries (18-34 years old) 
IJM
43,7

1588

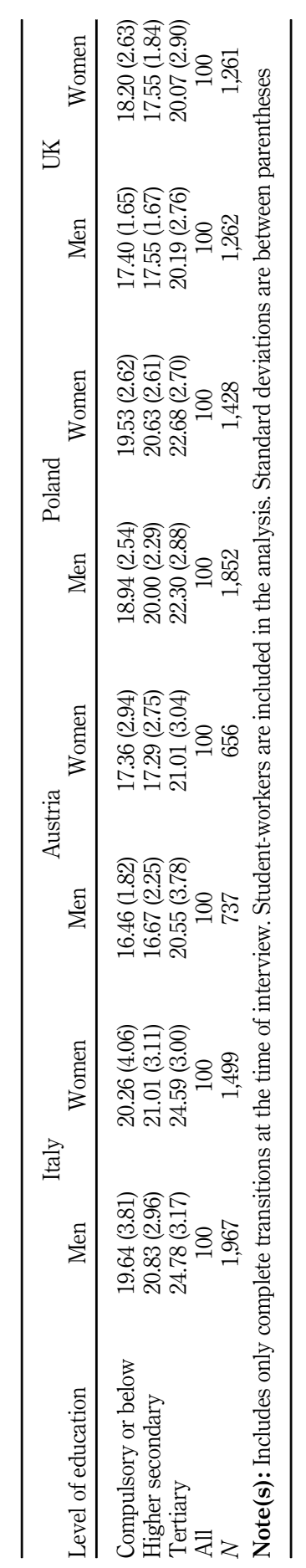

Table 4.

Mean Age When

Individuals 18-34

Years Old attained

Their First Regular Job

by Level of Education

and Gender in Selected

European Countries 


\begin{tabular}{|c|c|c|c|c|c|c|c|}
\hline $\begin{array}{l}\text { Level of } \\
\text { education }\end{array}$ & $\begin{array}{l}\% \\
\text { compl. }\end{array}$ & $\begin{array}{c}\text { Men } \\
\text { Transition } \\
\text { completed } \\
\text { Mean (SD) }\end{array}$ & $\begin{array}{c}\text { All } \\
\text { Mean (SD) }\end{array}$ & $\begin{array}{c}\% \\
\text { compl. }\end{array}$ & $\begin{array}{l}\text { Women } \\
\text { Transition } \\
\text { completed } \\
\text { Mean (SD) }\end{array}$ & $\begin{array}{c}\text { All } \\
\text { Mean (SD) }\end{array}$ & \multirow{6}{*}{1589} \\
\hline \multicolumn{8}{|l|}{ Italy } \\
\hline $\begin{array}{l}\text { Compulsory or } \\
\text { below }\end{array}$ & 63.82 & $5.72(4.03)$ & $7.86(5.25)$ & 31.65 & $6.02(4.29)$ & $11.44(6.05)$ & \\
\hline Higher secondary & 74.85 & $2.29(2.57)$ & 3.34 (3.54) & 58.02 & 2.49 (2.79) & $4.89(4.61)$ & \\
\hline Tertiary & 80.49 & 0.88 (1.44) & $1.48(2.25)$ & 72.42 & $0.97(1.47)$ & $1.85(2.51)$ & \\
\hline All & 72.60 & $2.90(3.32)$ & $4.32(4.56)$ & 55.44 & $2.46(3.13)$ & $5.67(5.75)$ & \\
\hline$N$ & 2,484 & 1,967 & 2,484 & 2,352 & 1,499 & 2,352 & \\
\hline \multicolumn{8}{|l|}{ Austria } \\
\hline $\begin{array}{l}\text { Compulsory or } \\
\text { below }\end{array}$ & 82.04 & $1.10(1.52)$ & $2.46(3.75)$ & 47.06 & $2.01(3.47)$ & $7.34(6.58)$ & \\
\hline Higher secondary & 82.71 & $0.28(0.97)$ & $1.26(3.20)$ & 76.22 & $0.48(1.62)$ & $2.63(4.65)$ & \\
\hline Tertiary & 91.75 & $0.32(0.87)$ & 0.49 (1.24) & 77.51 & $0.19(0.62)$ & $1.64(3.36)$ & \\
\hline All & 85.52 & $0.44(1.09)$ & $1.22(2.92)$ & 72.07 & $0.51(1.70)$ & $2.99(4.97)$ & \\
\hline$N$ & 844 & 737 & 844 & 904 & 656 & 904 & \\
\hline \multicolumn{8}{|l|}{ Poland } \\
\hline $\begin{array}{l}\text { Compulsory or } \\
\text { below }\end{array}$ & 73.26 & $3.12(2.57)$ & $4.89(4.59)$ & 37.38 & $3.36(2.83)$ & $8.49(6.08)$ & \\
\hline Higher secondary & 88.01 & 0.94 (1.75) & $1.57(2.96)$ & 63.93 & $1.42(2.19)$ & $3.94(4.67)$ & \\
\hline Tertiary & 97.20 & $0.32(0.89)$ & $0.46(1.34)$ & 85.38 & $0.35(1.04)$ & $1.10(2.31)$ & \\
\hline All & 89.18 & 0.92 (1.77) & $1.58(3.07)$ & 73.00 & 0.87 (1.79) & $2.78(4.25)$ & \\
\hline$N$ & 2,076 & 1,852 & 2,076 & 2,084 & 1,428 & 2,084 & \\
\hline \multicolumn{8}{|l|}{ United Kingdom } \\
\hline $\begin{array}{l}\text { Compulsory or } \\
\text { below }\end{array}$ & 83.34 & $0.66(1.26)$ & $2.03(4.03)$ & 58.47 & $1.20(2.25)$ & $4.58(5.58)$ & Table 5. \\
\hline Higher secondary & 91.52 & $0.52(1.18)$ & $0.91(2.02)$ & 77.37 & $0.54(1.15)$ & $2.35(4.14)$ & Distribution of \\
\hline Tertiary & 94.30 & $0.22(0.79)$ & $0.57(1.84)$ & 85.78 & $4.05(4.99)$ & $1.30(3.17)$ & durations of the $1 \mathrm{w}$ \\
\hline All & 91.33 & $0.41(1.01)$ & $0.95(2.47)$ & 79.77 & 0.42 (1.13) & 2.04 (3.98) & $\begin{array}{l}\text { for complete a1 } \\
\text { incomplete transitio }\end{array}$ \\
\hline$N$ & 1,424 & 1,262 & 1,424 & 1,610 & 1,261 & 1,610 & in selected European \\
\hline \multicolumn{7}{|c|}{$\begin{array}{l}\text { Note(s): Student-workers are included in the analysis } \\
\text { Source(s): Author's own elaborations based on EU-SILC data }\end{array}$} & $\begin{array}{l}\text { countries (by education } \\
\text { level; } 18-34 \text { Years old) }\end{array}$ \\
\hline
\end{tabular}

Table 4 shows that the gap in the mean age when young people get their first regular job is particularly evident between Italy, on the one hand, and Austria, on the other hand, in particular for the low and medium levels of education, with a high share of Austrians starting to work before completing their studies. Indeed, in Italy, young people with only compulsory education attain the first regular job, on average, at 20, but 3 years earlier in Austria, 2 years earlier in the UK and 1 year earlier in Poland. The gap for the tertiary educated is greater than four years on average between Italy, on the one hand, and Austria and the UK, on the other hand, while Poland has an intermediate position (around 22 years).

In all the countries, the share of women with tertiary education is much higher than for men, probably due to the fact that gender inequality decreases for higher levels of education (Manning and Swaffield, 2008). Indeed, the mean age when individuals gain their first regular job is systematically higher for women with a low and a medium level of education. The gender gap is maximum in Austria for low educated, with a mean age of 16.46 years for men and 17.36 for women. 


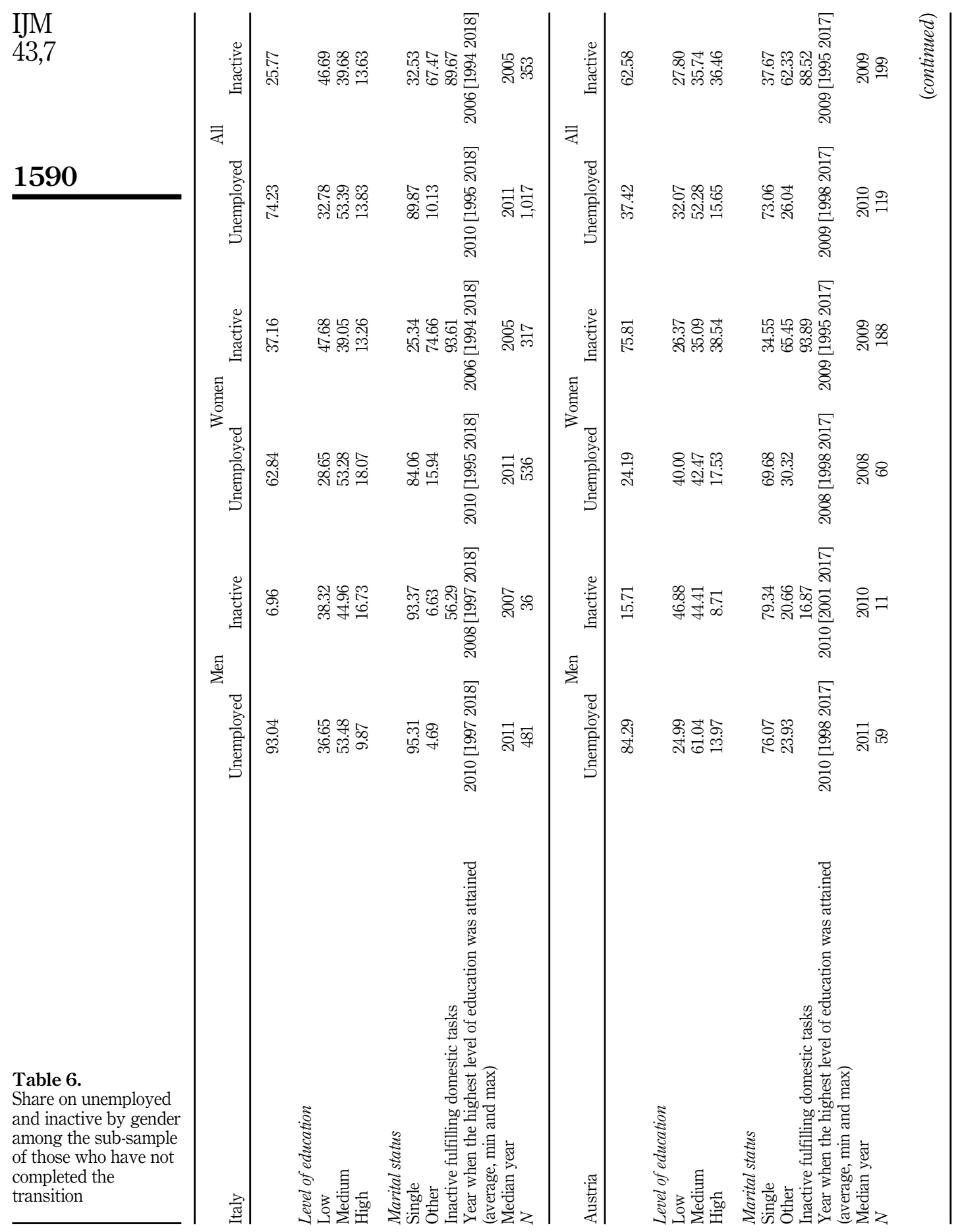




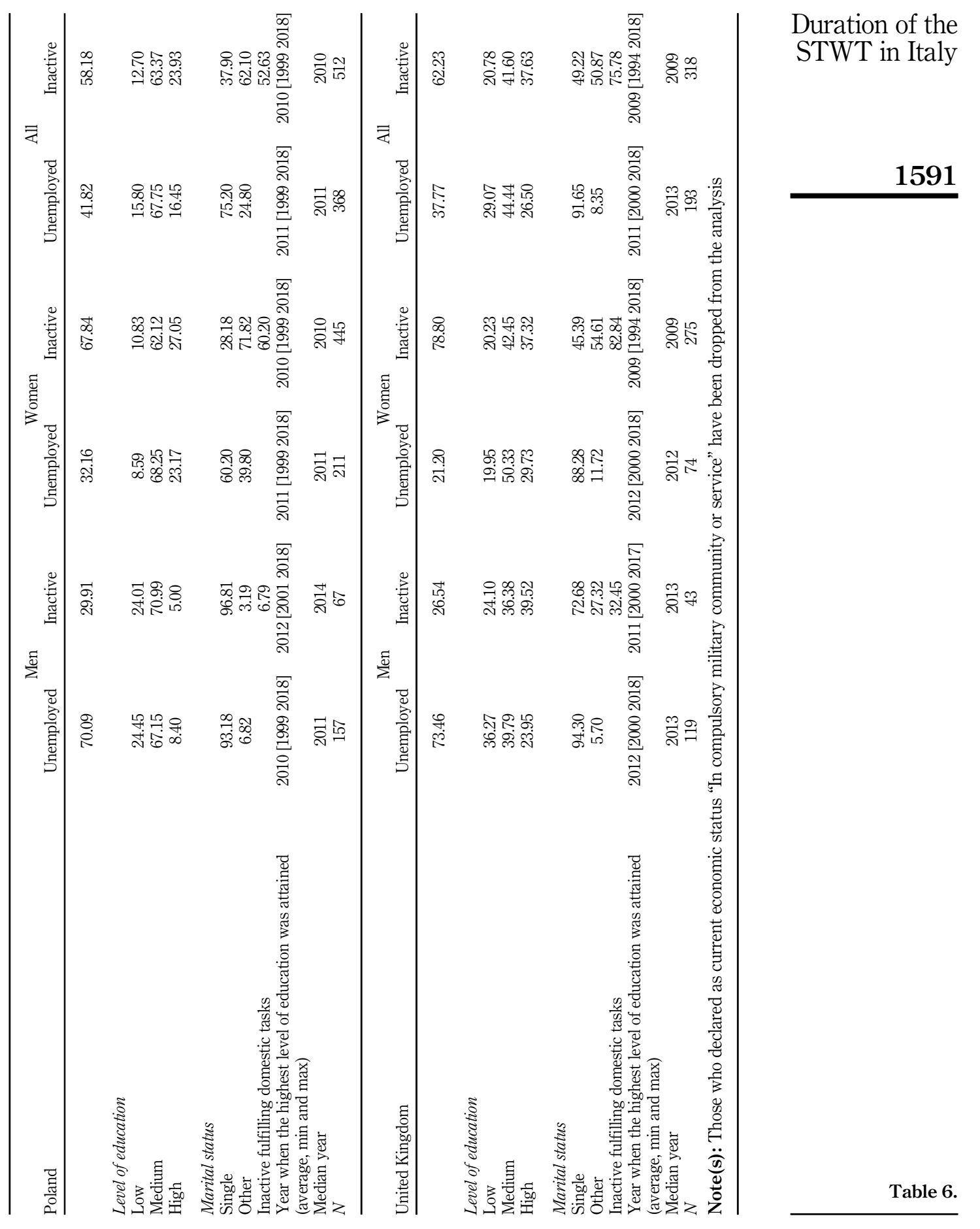


IJM

43,7

1592

Young Italians who had completed the transition at the time of interview (Table 5) are only $72.60 \%$ of men and $55.44 \%$ of women, with a gap of at least of $13 \%$ from other countries. It does not reduce also for the tertiary educated: while in Italy around 8 out 10 men and 7 out 10 women have completed the transition, in the other countries, they are more than the $90 \%$ of men and around $80 \%$ of women. However, the gap in mean durations between Italy, on the one side, and the other countries, on the other side, is still higher while differences by gender are negligible. Indeed, in Italy the duration of completed transitions equals 2.9 and 2.46 years for men and women respectively, while in the other countries it does not reach one year for both men and women. The gap is even higher when we focus on the low-educated, reaching 6 years in Italy, 3 years in Poland and 1 year in the UK.

The mean duration of the STWT including the in-transition at the time of the interview reaches 4 years for men and 5 years for women in Italy, against 12 months for men and between 2 and 3 years for women in the other countries.

It is reasonable to suppose that some of the in-transition at the time of interview is exiting the labor market for ever. Table 6 shows that these individuals are inactive in Austria, Poland and the UK while being unemployed in Italy, confirming the involuntary nature of incomplete transitions. In all countries, inactivity is more frequent among women.

\subsection{The determinants of duration}

Table 7 shows the results of the Cox semi-parametric function for the determinants of the duration of the STWT by gender for all the countries analyzed. The estimates include studentworkers only if their work activity is linked to the vocational path of education; if not, they are excluded as they have not experienced the transition. We propose two models for the analysis. Model 1 contains only a selection of strictly exogenous covariates. They include nationality, gender, level and type of education, age and place of residence (in terms of degree of urbanization). Model 2 adds to these covariates civil status, the regional unemployment rate and a dummy reflecting whether the individual has received any unemployment benefit. Cross-country comparisons are made explicit interacting the covariates with the country dummy variables. Models 1 and 2 are presented for the entire sample and by gender. The reference categories are: Italian migrants from the EU and Italian migrants from other countries while EU-migrants were not considered for Poland due to the extremely low number of individuals in the sample. Italian singles are the reference category for marital status while Italian low-educated people are the reference category for the level of education. No one in the sample from the UK has a postsecondary level of education as defined by EU-SILC (ISCED level 4, indicating post-secondary, not tertiary education) while in the Italian sample there are not student-workers with a vocational path of education. Finally, no one in the UK sample perceives a benefit for unemployment.

Coefficients are reported in terms of hazard ratios, obtained by taking the exponential of the estimated coefficient. A value greater than 1 for the hazard ratio denotes that an increase in the covariate correlates with an increase in the hazard rate. This implies an increase in the instantaneous job-finding rate at every duration and, at the same time, a reduction in the duration of the STWT. Conversely, figures smaller than 1 mean a reduction of the hazard rate, i.e. a longer survival time, associated to that covariate.

The estimated models confirm the expected outcomes. In comparison to migrants residing in Italy, migrants from extra-EU countries experience everywhere a longer STWT. When the country of origin is another EU country, migrant women have a longer transition only in Austria. The analysis shows fast transitions for men while, for women, being not single increases the duration of transition only in Italy and Poland, with hazard rates, respectively, of 0.67 and 0.63 .

Being more educated significantly reduces the STWT everywhere, with a hazard which increases with education and reaches its maximum for the tertiary educated in the UK and Poland, with a hazard rate higher than 3 for men and even higher than 4 for women. In the 


\begin{tabular}{|c|c|c|c|c|c|c|c|}
\hline \multirow[b]{2}{*}{ Variables } & \multicolumn{2}{|c|}{ Men } & \multicolumn{2}{|c|}{ Women } & \multicolumn{2}{|c|}{ All } & \\
\hline & Model 1 & Model 2 & Model 1 & Model 2 & Model 1 & Model 2 & \\
\hline Women & - & - & - & - & $0.595^{* * * * *}$ & $0.622^{\text {***** }}$ & \\
\hline $\begin{array}{l}\text { Nationality (ref. migrant IT) } \\
\text { Migrant from EU Austria } \\
\text { Migrant from EU UK } \\
\text { Migrant extra EU Austria } \\
\text { Migrant extra EU Poland } \\
\text { Migrant extra EU UK }\end{array}$ & $\begin{array}{l}1.024 \\
1.417^{\text {***** }} \\
0.874 \\
0.475 \\
0.690^{\text {**** }}\end{array}$ & $\begin{array}{l}1.058^{\text {**** }} \\
1.351^{\text {*** }} \\
0.895 \\
0.436 \\
0.646^{\text {**** }}\end{array}$ & $\begin{array}{l}0.724^{\text {*** }} \\
1.321^{\text {***** }} \\
0.558 \\
0.526 \\
0.542^{\text {***** }}\end{array}$ & $\begin{array}{l}0.757^{*} \\
1.329^{* * * *} \\
0.719^{\text {*** }} \\
0.576 \\
0.582^{\text {**** }}\end{array}$ & $\begin{array}{l}0.844^{*} \\
1.378^{\text {****** }} \\
0.698^{\text {****** }} \\
0.524^{\text {* }} \\
0.601^{\text {**** }}\end{array}$ & $\begin{array}{l}0.900 \\
1.349^{\text {**** }} \\
0.818^{\text {*** }} \\
0.542^{\text {* }} \\
0.596^{\text {**** }}\end{array}$ & 1593 \\
\hline $\begin{array}{l}\text { Marital status (ref. single IT) } \\
\text { Single AT } \\
\text { Single PL } \\
\text { Single UK } \\
\text { Other (married, separate., etc.) AT } \\
\text { Other (married, separate., etc.) IT } \\
\text { Other (married, separate., etc.) PL } \\
\text { Other (married, separate., etc.) UK }\end{array}$ & & $\begin{array}{l}3.120^{\text {****** }} \\
1.493^{\text {******* }} \\
2.455^{\text {****** }} \\
3.209^{\text {******* }} \\
1.339^{\text {***** }} \\
2.113^{\text {***** }} \\
3.319^{\text {***** }}\end{array}$ & & $\begin{array}{l}2.278^{* * * *} \\
1.104 \\
2.464^{* * *} \\
1.253^{* * *} \\
0.669^{* * *} \\
0.635^{* *} \\
1.893^{* * *}\end{array}$ & & $\begin{array}{l}1.539^{\text {**** }} \\
0.816^{\text {*** }} \\
1.509^{\text {*** }} \\
1.096^{\text {*** }} \\
0.829^{\text {***** }} \\
0.659^{\text {**** }} \\
1.448^{\text {** }}\end{array}$ & \\
\hline $\begin{array}{l}\text { Benefits for unemployment (ref. IT) } \\
\text { Benefits AT } \\
\text { Benefits PL }\end{array}$ & & $\begin{array}{l}0.677^{* * * *} \\
0.480^{*}\end{array}$ & & $\begin{array}{l}0.777^{* * *} \\
0.473^{* *}\end{array}$ & & $\begin{array}{l}0.736^{\text {**** }} \\
0.467^{\text {**** }}\end{array}$ & \\
\hline $\begin{array}{l}\text { Level of education (low IT) } \\
\text { Low AT } \\
\text { Low PL } \\
\text { Low UK } \\
\text { Upper secondary ed. AT } \\
\text { Upper secondary ed. IT } \\
\text { Upper secondary ed. PL } \\
\text { Upper secondary ed. UK } \\
\text { Post-secondary AT } \\
\text { Post-secondary IT } \\
\text { Post-secondary PL } \\
\text { Tertiary education AT } \\
\text { Tertiary education IT } \\
\text { Tertiary education PL } \\
\text { Tertiary education UK } \\
\text { Vocational AT } \\
\text { Vocational PL } \\
\text { Vocational UK } \\
\text { Vocational student-worker AT } \\
\text { Vocational student-worker UK }\end{array}$ & $\begin{array}{l}1.163 \\
1.203 \\
1.987^{\text {****** }} \\
0.9398 \\
1.868^{\text {****** }} \\
2.393^{\text {****** }} \\
3.162^{\text {****** }} \\
0.992 \\
1.889^{\text {*** }} \\
1.414 \\
2.005 \\
2.535^{\text {***** }} \\
3.382^{\text {***** }} \\
3.403^{\text {***** }} \\
0.695 \\
1.112 \\
0.774^{*} \\
5.943^{\text {***** }} \\
2.999^{\text {***** }}\end{array}$ & 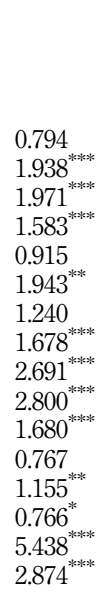 & 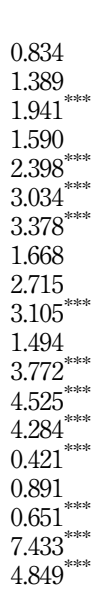 & $\begin{array}{l}1.617^{* * * *} \\
2.191^{* * * *} \\
2.483^{* * * *} \\
1.800^{* * * *} \\
1.574^{* * *} \\
2.429^{* * * *} \\
2.547^{* * * *} \\
1.736^{* * * *} \\
3.355^{* * * *} \\
3.942^{* * *} \\
2.332^{* * * *} \\
0.481^{* * * *} \\
0.907 \\
0.644^{* * * *} \\
7.092^{* * * *} \\
4.927^{* * * *}\end{array}$ & 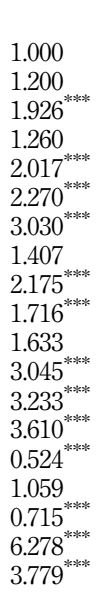 & 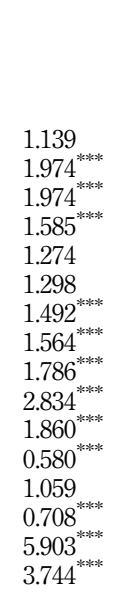 & \\
\hline $\begin{array}{l}\text { Degree of urbanization (ref. rural IT) } \\
\text { Rural area AT } \\
\text { Rural area PL } \\
\text { Rural area UK } \\
\text { Intermediate degree AT } \\
\text { Intermediate degree IT } \\
\text { Intermediate degree PL } \\
\text { Intermediate degree UK } \\
\text { City AT } \\
\text { City IT } \\
\text { City PL } \\
\text { City UK }\end{array}$ & $\begin{array}{l}1.980 \\
1.150 \\
1.059 \\
2.001 \\
0.999 \\
1.131 \\
0.935 \\
1.587 \\
0.798^{\text {***** }} \\
1.101\end{array}$ & $\begin{array}{l}0.995 \\
0.991 \\
0.972 \\
0.885 \\
0.851^{\text {*** }} \\
0.800^{\text {**** }} \\
0.958 \\
0.968\end{array}$ & $\begin{array}{l}2.326 \\
0.785 \\
1.155 \\
2.516^{*} \\
1.070 \\
0.826 \\
1.232^{\text {**** }} \\
2.156 \\
0.983 \\
0.968\end{array}$ & $\begin{array}{l}1.071 \\
1.066 \\
1.048 \\
1.056 \\
0.904 \\
0.969 \\
1.160^{* *} \\
0.885\end{array}$ & $\begin{array}{l}2.006^{*} \\
1.060 \\
1.092^{\text {*** }} \\
2.147^{*} \\
1.023 \\
1.073 \\
1.058 \\
1.769 \\
0.871^{\text {***** }} \\
1.157\end{array}$ & $\begin{array}{l}1.055 \\
1.007 \\
1.003 \\
0.970 \\
0.900^{*} \\
0.828^{* * * *} \\
1.074 \\
0.943 \\
\end{array}$ & $\begin{array}{r}\text { Table } 7 . \\
\text { Determinants of } \\
\text { STWT duration by } \\
\text { gender using the Cox } \\
\text { semi-parametric } \\
\text { function }^{(*)}\end{array}$ \\
\hline
\end{tabular}




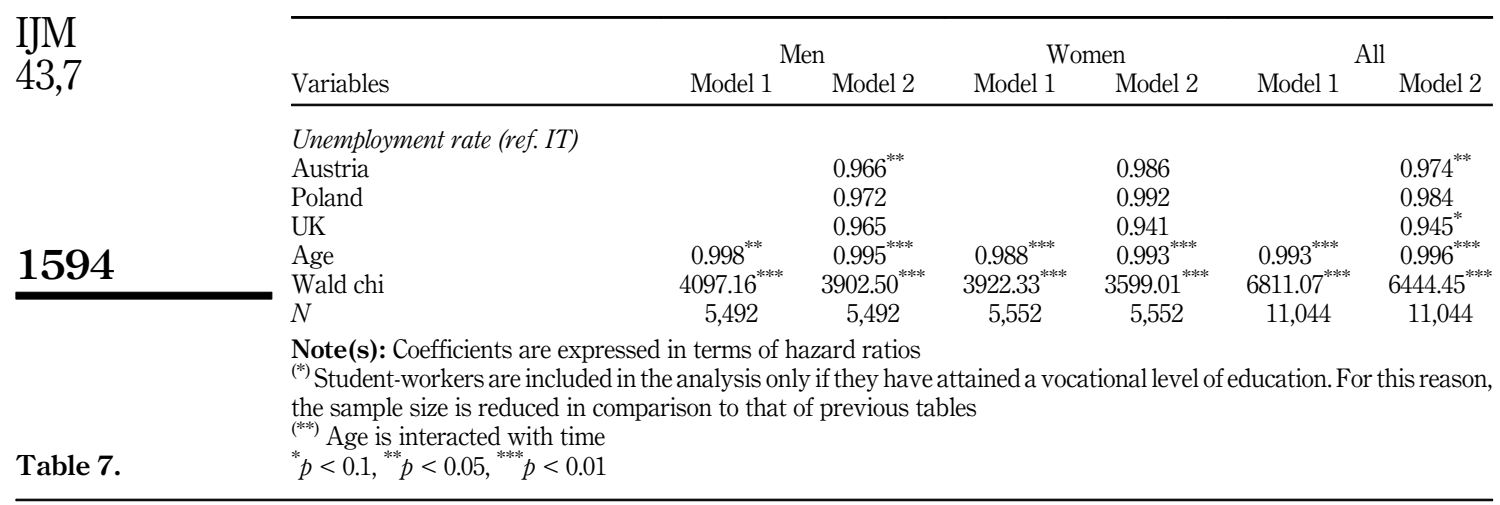

other countries, the premium in terms of reduction in the STWT duration is higher for women, as well. Another important result concerns the effectiveness of the vocational path of education in reducing the duration of the STWT in Austria, where the hazard rates are higher than 5 for men and even higher than 7 for women. We find similar results, even if with smaller hazard rates, for the UK, confirming that in these countries a vocational path of education is a significant entry door to the labor market.

As for the degree of urbanization of the place of residence, the only significant result concerns the penalty of Italian young people living in densely populated areas in comparison to those living in rural areas, but this penalty appears to be significant only for men. Finally, the regional unemployment rate and the unemployment benefits perception tend to significantly penalize the Austrians but not the Italians. This outcome suggests that labor market characteristics are the main factor of the Italian young people disadvantage.

In Table 8, we collapse one of our initial assumptions, and consider completed the transition also for those who have got a stable job in the past but are unemployed or inactive at the time of the interview. They represent about the $33 \%$ of Italian and Polish young women; for men the maximum share is in Italy $(13.69 \%)$. Results are substantially similar to the previous ones, highlighting only some reduction in the level of hazard rates.

Figure 1 shows the smoothed baseline hazard estimates by education level for the entire sample and by gender. As already noted in the methodological section, these functions, for which we do not make any assumption regarding the shape, measure the probability distribution of exiting the STWT at a given point in time for those who are still in the transition.

Through the flexible semi-parametric approach, we cannot correct for unobserved heterogeneity introducing the correction for frailty. However, instead of imposing a theoretical pattern to the hazard curve, we observe its empirical pattern, making it possible to account for its nonlinearity. Indeed, we find a nonlinear hazard function: it is increasing at the beginning and decreasing subsequently. In other words, the probability of exiting the transition to a job increases in the first period, but shrinks after some time. This is a very interesting result that parametric models do not allow detecting, as they only allow for positive or negative duration dependence. In reason of the previous descriptive and econometric results, it may be due to the fact that in Austria, Poland and the UK the majority of young people find a job very quickly, in most cases during the first year of the transition. Therefore, those who remain after the first year in the STWT are mainly those who choose to be inactive for whatever reason. Conversely, for Italian young people, especially the low-educated one, the hazard is very low during the whole period of STWT, indicating a very harsh scenario.

The increasing hazard rate for low and medium levels of education is in line with previous findings by Pastore et al. (2020), based on parametric survival models of positive duration 


\begin{tabular}{|c|c|c|c|c|c|}
\hline \multirow[b]{2}{*}{$\underline{\text { Variables }}$} & \multicolumn{2}{|c|}{ Men } & \multicolumn{2}{|c|}{ Women } & \multirow{2}{*}{$\begin{array}{l}\text { Duration of the } \\
\text { STWT in Italy }\end{array}$} \\
\hline & Model 2 & Model 2 & Model 1 & Model 2 & \\
\hline \multicolumn{6}{|l|}{ Nationality (ref. migrant IT) } \\
\hline Migrant from EU Austria & 1.000 & 1.023 & $0.661^{* * * *}$ & $0.707^{* * * *}$ & \\
\hline Migrant from EU UK & $1.529^{* * * *}$ & $1.391^{* * * *}$ & $1.472^{* * * *}$ & $1.412^{* * * *}$ & \\
\hline Migrant extra EU Austria & 0.887 & 0.886 & $0.568^{* * * * *}$ & $0.720^{* * * *}$ & \\
\hline Migrant extra EU Poland & $0.531^{*}$ & $0.493^{*}$ & $0.739^{* * *}$ & $0.781^{* * *}$ & 1595 \\
\hline Migrant extra EU UK & $0.800^{*}$ & $0.739^{* * * *}$ & $0.572^{* * * *}$ & $0.580^{* * * *}$ & \\
\hline \multicolumn{6}{|l|}{ Marital status (ref. single IT) } \\
\hline Single AT & & $1.760^{* * * *}$ & & 0.910 & \\
\hline Single PL & & 0.887 & & $0.590^{* * * *}$ & \\
\hline Single UK & & 1.418 & & 1.257 & \\
\hline Other (married, separate., etc.) AT & & $1.847^{* * * *}$ & & $0.606^{* * * *}$ & \\
\hline Other (married, separate., etc.) IT & & $1.210^{* * * *}$ & & $0.561^{* * * *}$ & \\
\hline Other (married, separate., etc.) PL & & $1.263^{* *}$ & & $0.432^{* * *}$ & \\
\hline Other (married, separate., etc.) UK & & $2.010^{* * * *}$ & & $1.069^{* * *}$ & \\
\hline \multicolumn{6}{|l|}{ Benefits for unemployment (ref. IT) } \\
\hline Benefits AT & & $0.738^{* * * *}$ & & $0.874^{* * *}$ & \\
\hline Benefits PL & & 0.746 & & 0.958 & \\
\hline \multicolumn{6}{|l|}{ Level of education (low IT) } \\
\hline Low AT & 1.240 & & 0.815 & & \\
\hline Low PL & 1.232 & & $1.751^{* * * *}$ & & \\
\hline Low UK & $2.277^{* * * *}$ & & $2.991^{* * * *}$ & & \\
\hline Upper secondary ed. AT & 1.321 & 0.971 & $2.502^{* * *}$ & $2.178^{* * * *}$ & \\
\hline Upper secondary ed. IT & $2.382^{* * * *}$ & & $4.870^{* * * *}$ & & \\
\hline Upper secondary ed. PL & $2.735^{* * * *}$ & $2.081^{* * * *}$ & $4.565^{* * * *}$ & $2.731^{* * * *}$ & \\
\hline Upper secondary ed. UK & $3.578^{\text {**** }}$ & $1.527^{* * * *}$ & $5.276^{* * * *}$ & $1.817^{* * * *}$ & \\
\hline Post-secondary AT & 1.366 & 1.072 & $2.934^{* * *}$ & $2.385^{* * * *}$ & \\
\hline Post-secondary IT & $2.248^{* * * *}$ & 1.266 & $7.896^{* * * *}$ & $2.163^{* * * *}$ & \\
\hline Post-secondary PL & $1.933^{* * *}$ & $1.536^{*}$ & $6.361^{* * * * *}$ & $3.634^{* * * *}$ & \\
\hline Tertiary education AT & $2.688^{* * *}$ & $1.906^{\text {**** }}$ & $3.187^{* * * *}$ & $3.024^{* * * *}$ & \\
\hline Tertiary education IT & $3.718^{* * * *}$ & $2.039^{* * * *}$ & $9.818^{* * * *}$ & $2.751^{* * * *}$ & \\
\hline Tertiary education PL & $4.085^{* * *}$ & $3.017^{* * * *}$ & $8.179^{* * * *}$ & $4.804^{* * * *}$ & \\
\hline Tertiary education UK & $4.054^{* * * *}$ & $1.664^{* * * *}$ & $7.577^{* * * *}$ & $2.565^{* * * *}$ & \\
\hline Vocational AT & 0.976 & 1.080 & $0.640^{* * * *}$ & $0.728^{* * *}$ & \\
\hline Vocational PL & 1.090 & $1.128^{* *}$ & $0.890^{* *}$ & $0.903^{*}$ & \\
\hline Vocational UK & 0.865 & 0.853 & 0.905 & 0.872 & \\
\hline Vocational student-worker AT & $3.908^{* * * *}$ & $3.464^{* * * *}$ & $5.098^{* * * *}$ & $4.683^{* * *}$ & \\
\hline Vocational student-worker UK & $2.951^{\text {**** }}$ & $2.673^{* * * *}$ & $4.493^{* * * *}$ & $4.257^{* * * *}$ & \\
\hline \multicolumn{6}{|l|}{ Degree of urbanization (ref. rural IT) } \\
\hline Rural area AT & 1.904 & & $2.746^{* * *}$ & & \\
\hline Rural area PL & 1.246 & & 1.146 & & \\
\hline Rural area UK & 1.051 & & 1.170 & & $\begin{array}{l}\text { Table } 8 . \\
\text { Tinonta }\end{array}$ \\
\hline Intermediate degree AT & 1.875 & 0.968 & $3.093^{* * * *}$ & $1.106^{*}$ & Determinants of \\
\hline Intermediate degree IT & 1.006 & 0.993 & 1.000 & $0.935^{*}$ & SIW I Duration by \\
\hline Intermediate degree PL & 1.224 & 0.973 & 1.175 & 1.017 & $\begin{array}{l}\text { Gender Using the ox } \\
\text { Semi-parametric }\end{array}$ \\
\hline Intermediate degree UK & 0.922 & 0.891 & $1.222^{* * * *}$ & 1.044 & $\begin{array}{l}\text { Sem1-paramerric } \\
\text { Function considering. }\end{array}$ \\
\hline City AT & 1.547 & $0.857^{* *}$ & $2.815^{* * * *}$ & 1.004 & r completed the \\
\hline City IT & $0.810^{* * * *}$ & $0.770^{* * * *}$ & $0.915^{*}$ & $0.779^{* * * *}$ & transition also for the \\
\hline City PL & 1.227 & 0.980 & 1.373 & $1.158^{* * * *}$ & $\begin{array}{l}\text { who had in the past a } \\
\text { w }\end{array}$ \\
\hline \multirow[t]{2}{*}{ City UK } & & 0.978 & & 0.914 & regular job but not in \\
\hline & & & & (continued) & $\begin{array}{l}\text { employment at the time } \\
\text { of interview }\end{array}$ \\
\hline
\end{tabular}




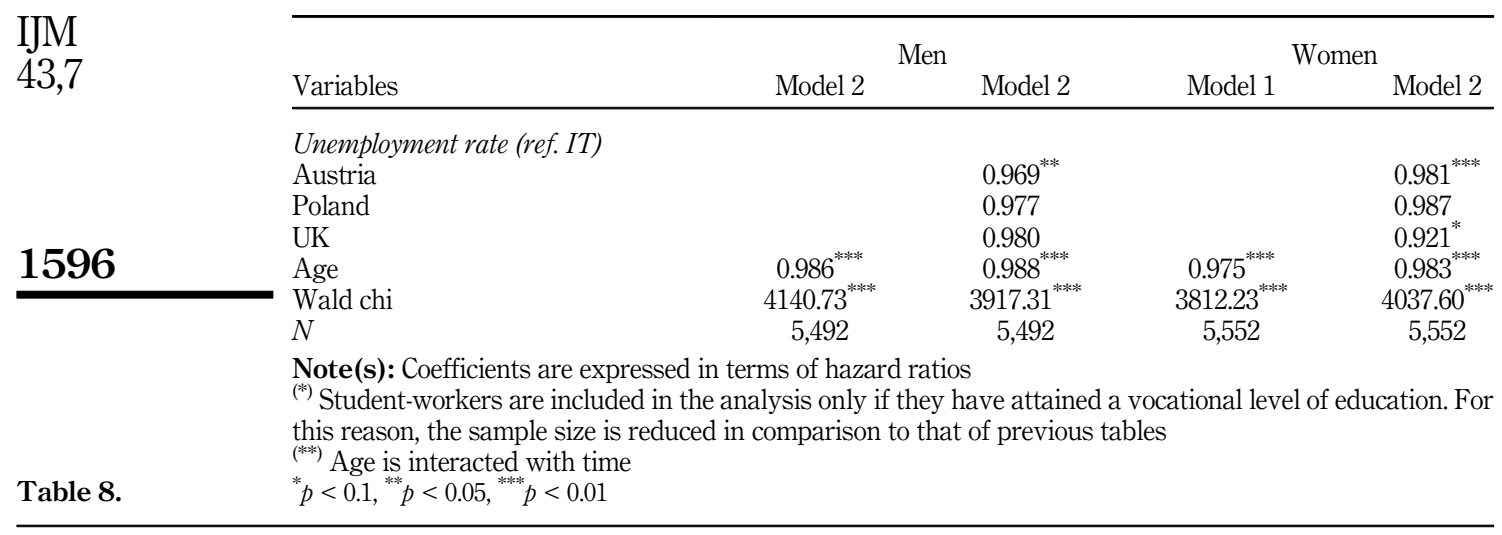

Figure 1.

Smoothed hazard estimates by education level and by gender

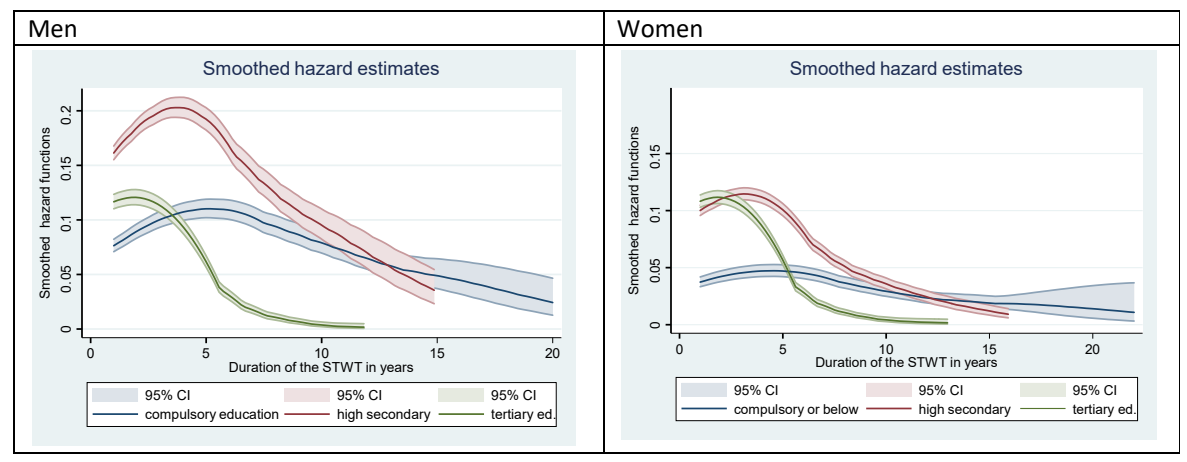

dependence. It suggests that some form of "learning by searching" is taking place: young people tend to learn how to search for their best job match and, at the same time, accumulate the work experience they need to overcome their experience gap compared to older adults, becoming more employable for firms (Pastore, 2015).

The finding regarding university graduates may be interpreted as a tendency to have an advantage in the labor market that should be exploited soon, because it reduces over time, probably because some university degrees are less in demand and force some young people into unemployment or inactivity. We do not have information on the field of study in the EUSILC data, but evidence coming from other studies suggests that not only Arts and Humanities, but also Geology, Psychology and Biology, as well as, more recently, Law, might decrease the probability of finding a job, at least in the early stage of the transition (see also Caroleo and Pastore, 2018; Anelli, 2020).

The average reduction in the hazard rate for university graduates after the first few years is especially prevalent among women. For men, the hazard rate seems to increase with the duration of the STWT, including university graduates. This might further strengthen the hypothesis that the field of study matters, because the fields of study mentioned above are especially chosen by women.

Another interesting feature of the figures is the high variability of the estimated distributions, as measured by the confidence interval of the functions at different duration levels. The intervals tend to dramatically increase with duration. In particular, they are shorter for the highly educated, regardless of gender, even if with a greater variability. This 
suggests that with increasing duration of the STWT, the heterogeneity of the sample increases dramatically and we have, on the one hand, some people with very high chances of finding a job after waiting for a long time and other people who tend to become discouraged and move to the inactive status.

\section{Discussion, conclusions and policy implications}

In this paper, we provide measures of the duration of the STWT by education and gender in Italy and compare them with those in three other European countries: Austria, Poland and the UK. The geographical perspective allows us to highlight better the hardship that Italian young people experience and the role of labor-market institutions and the education system. Looking only at the transition to any type of work, as has been done in previous research (EUROSTAT, 2012), may not be fully satisfactory in the case of Italy because of two-tier reforms which increased the share of fixed-term contracts. That is why we examined transition to a "regular job" (at least 6 months), which is much closer to the ILO (2020) concept of a stable job or a job that is considered satisfactory for a young person. Only then can the young person consider the STWT complete.

We distinguish between complete durations, which are calculated only for those who have obtained a stable job at the time of interview, and total durations, which include also those who are still in-transition at the time of the interview. Cross-country differences are already apparent in terms of education attainment. In Italy, only two out of 10 reach tertiary education, while this figure is over 30\% in Austria and Poland and 40\% in the UK. In all the countries studied, women are more educated than men, but they usually experience longer STWT.

The STWT is longer in Italy, where it reaches a mean average of just over two years for complete durations, with remarkable differences by education and gender. Italian women with a low level of education have a mean duration of six years for complete duration and 11 years when including incomplete transitions. The condition of Italian men is slightly better, with 5.72 and 7.86 years, respectively. The mean durations in the other countries considered are systematically lower.

Moreover, we estimated a semi-parametric Cox model for the duration by gender in order to better highlight the determinants at an individual level. To detect differences across countries, we interact each variable with the country dummies in the same pooled regression.

The survival function shows that being a woman is associated with a significant penalty. The coefficient for gender shows a ceteris paribus hazard rate of 0.6. Being married increases the duration of the STWT for women while reducing it for men. The cross-country comparisons show a harsh scenario for Italian young people, which cannot rely on an effective vocational path. In Italy, living in an urban area may reduce the labor-market opportunities for young people. However, when we control for the local levels of unemployment most of this disadvantage disappears.

The strong penalty Italian young people experience in the STWT may explain why an increasing number, especially with high education, are moving abroad to find a job (see Cattaneo et al., 2019 and references therein).

Our analysis suggests that, overall, in Italy, if a young person graduates with a three-plustwo-year university degree at 24-25 years old (but with a deviation from the mean of almost three years, reaching therefore in some cases 28 years of age; see, among others, Aina et al., $2015,2019,2021)$, he/she will find a more or less stable job at the age of 27-28 years on average; a large proportion of them, however, would not achieve this until 30-31 years of age. In the UK, a young person typically graduates at the age of about 22 years and finds a stable job at the age of 23 years. The consequences of these differences are dramatic in several respects. At 30-31 years of age, the UK contemporary of a young Italian peer has already acquired an average of 7-8 years of work experience and her/his human capital is clearly
Duration of the STWT in Italy 
IJM

43,7

superior to that of an Italian of the same age. It will also include a work-related component, which is still almost completely missing in Italian peers.

Moreover, if long durations are the consequence of a rigid and sequential STWT regime, on the other hand, they explain, in turn, low enrolment into higher education, especially tertiary-education attainment, as it dramatically affects the ex ante returns to education, on which such decisions are based (Altonji, 1993). More investment in education, vocational paths of education and policies aimed at increasing the proportion of those with a high level of education could help give young people the adequate skills required in the labor market. However, it is apparent that these initiatives will not be sufficient if they are not associated with a range of active labor policies aimed at helping young people to enter the labor market.

Last but not least, since women tend to have the same work and career aspirations as men, they find themselves in the condition of establishing a family and deciding to have children at an age when their fertility is much lower, which partly explains why the country has moved in a few decades from being one of the countries with the highest fertility rate in the EU to one of the lowest. We submit, therefore, that a long STWT should be considered an important and integral part of what Bettio (1998) called the Mediterranean model of the relationship between participation and fertility.

The policy implications of this study are manifold and important. First, the Italian STWT regime, like all the other South Mediterranean regimes, should aim to restore stable economic growth to absorb the large cyclical component of youth unemployment and begin to reduce the longest durations of transition. Second, to reduce also the structural component of youth unemployment and further reduce the long-run average value of the duration of the STWT, it is necessary to include elements of duality in the education system, such as work-related learning, vocational education and training at a the higher-secondary- and tertiary-level of education, apprenticeships and an active labor-market policy to a much larger extent than currently exists.

\section{Notes}

1. The following web site illustrates the methodology and results of the survey: https://ec.europa.eu/ eurostat/documents/1978984/6037334/Explanatory-notes-AHM-2009.pdf.

2. We thank an anonymous referee of the journal for suggesting us this extension of the study.

3. We thank an anonymous referee of the journal for suggesting this robustness check.

4. We thank on anonymous referee of the Journal for this useful interpretation.

5. Note that the sample size for the UK is reduced because the information on the year of achievement of a stable job (pl190) presents missing values in a certain portion of the cases. All the elaborations use sample weights to correctly infer them to the whole population.

\section{References}

Aina, C., Baici, E., Casalone, G. and Pastore, F. (2015), "Il ritardo alla laurea: cause, conseguenze e rimedi”, Scuola Democratica, Vol. 4 No. 2, pp. 273-294.

Aina, C., Baici, E., Casalone, G. and Pastore, F. (2019), "Delayed graduation and University Dropout: a review of theoretical approaches", Discussion Papers 12601, IZA.

Aina, C., Baici, E., Casalone, G. and Pastore, F. (2021), "The determinants of University Dropout: a review of the socio-economic literature", Socio-Economic Planning Studies, 28 June, 101102, ISSN 0038-0121, doi: 10.1016/j.seps.2021.101102 (forthcoming).

Altonji, J.G. (1993), "The demand for and return to education when education outcomes are uncertain”, Journal of Labor Economics, Vol. 11 No. 1, pp. 48-83.

Anelli, M. (2020), "The long-run labor market effect of university field of study", Policy Brief, University Bocconi, Milan. 
Arulampalam, W. (2001), "Is unemployment really scarring?: effects of unemployment experiences on wages", The Economic Journal, Vol. 111 No. 475, pp. F585-F606.

Bell, D.N.F. and Blanchflower, D.G. (2010), "Youth unemployment: déjà vu?”, Discussion Paper, 4705, IZA, Bonn.

Bettio, F. (1998), "A Mediterranean perspective on the breakdown of the relationship between participation and fertility”, Cambridge Journal of Economics, Vol. 22 No. 2, pp. 137-171.

Caroleo, F.E. and Pastore, F. (2018), "Overeducation at a glance. Determinants and wage effects of the educational mismatch based on AlmaLaurea data", Social Indicator Research, Vol. 137 No. 9, pp. 999-1032.

Caroleo, F.E., Rocca, A., Mazzocchi, P. and Quintano, C. (2020), "Being NEET before and after the economic crisis: an analysis of micro and macro determinants", Social Indicator Research, Vol. 149, pp. 991-1024, doi: 10.1007/s11205-020-02270-6.

Cattaneo, M., Malighetti, P. and Paleari, S. (2019), “The Italian brain drain: cream and milk”, Higher Education, Vol. 77 No. 4, pp. 603-622.

De Angelis, I., Mariani, V., Modena, F. and Montanaro, P. (2016), “Academic enrolment, careers and student mobility in Italy", Questioni di Economia e Finanza (Occasional Papers) 354, Bank of Italy, Economic Research and International Relations Area.

EUROSTAT (2012), School-to-work Transition Statistics, Eurostat, Luxembourg.

Fisher, L.D. and Lin, D.Y. (1999), "Time-dependent covariates in the Cox proportional hazards regression model", Annual Reviews in Public Health, Vol. 20, pp. 145-157.

Heckman, J.J. and Borjas, G.J. (1980), "Does unemployment cause future unemployment? Definitions, questions and answers from a continuous time model of heterogeneity and state dependence", Economica, Vol. 47 No. 187, pp. 247-283.

Heckman, J. and Singer, B. (1984), "The identifiability of the proportional hazard model", Review of Economic Studies, Vol. 51 No. 2, pp. 231-241.

ILO (2020), "Stages of the school-to-work transition: Geneva", available at: https://ilostat.ilo.org/ glossary/school-to-work-transition-stages/2020.

Korpi, T. and Levin, H. (2001), "Precarious footing: temporary employment as a stepping stone out of unemployment in Sweden", Work, Employment and Society, Vol. 15 No. 1, pp. 127-148.

Lancaster, T. (1979), "Econometric methods for the duration of unemployment", Econometrica, Vol. 47, pp. 939-956.

Manning, A. and Swaffield, J. (2008), "The Gender Gap in early-career wage growth", Economic Journal, Vol. 118 No. 530, pp. 983-1024.

Meyer, B.D. (1990), “Unemployment insurance and unemployment spell”, Econometrica, Vol. 85 No. 4, July, pp. 752-782.

Nickell, S.J. (1979), "Estimating the probability of leaving unemployment", Econometrica, Vol. 47, pp. 1249-1264.

OECD (various years), Education at a Glance 2010: OECD Indicators, OECD Publishing, Paris.

Pastore, F. (2015), The Youth Experience Gap: Explaining National Differences in the School-to-work Transition, Springer International Publishing AG, Heidelberg.

Pastore, F. (2018), “Why is youth unemployment so high and different across countries?”, IZA World of Labor, Vol. 420, doi: 10.15185/izawol.420.

Pastore, F., Quintano, C. and Rocca, A. (2020), "Stuck at a crossroads? The duration of the Italian school-to-work transition", International Journal of Manpower, Vol. 42 No. 3, pp. 442-469, doi: 10.1108/IJM-05-2020-0199.

Pastore, F., Quintano, C. and Rocca, A. (2021), "Some young people have all the luck! the duration dependence of the school-to-work transition in Europe", Labour Economics, Vol. 70, doi: 10. 1016/j.labeco.2021.101982. 
IJM

43,7

1600

Quintini, G., Martin, J.P. and Martin, S. (2007), “The changing nature of the school-to-work transition process in OECD countries", Discussion Paper 2582 January, IZA.

Raffe, D. (2008), "The concept of transition system”, Journal of Education and Work, Vol. 21 No. 4, pp. 277-296.

Ryan, P. (2001), "The school-to-work transition: a cross-national perspective", Journal of Economic Literature, Vol. 39 No. 1, pp. 34-92.

Therneau, T. and Grambisch, P.M. (2001), Modeling Survival Data: Extending the Cox Model, Springer-Verlag, New York.

\section{Further reading}

Anelli, M. (2018), “University to work transition”, Policy Brief, Università Bocconi.

Atkinson, A.B. and Micklewright, J. (1991), "Unemployment compensation and labour market transitions: a critical review", Journal of Economic Literature, Vol. 29 No. 4, pp. 1679-1727.

Pastore, F. (2019), "Why so slow? The school-to-work transition in Italy", Studies in Higher Education, Vol. 44 No. 8, pp. 1-14.

van den Berg, G.J. and van Ours, J.C. (1996), "Unemployment dynamics and duration dependence", Journal of Labour Economics, Vol. 14 No. 1, pp. 100-125.

\section{Corresponding author}

Antonella Rocca can be contacted at: rocca@uniparthenope.it

For instructions on how to order reprints of this article, please visit our website:

www.emeraldgrouppublishing.com/licensing/reprints.htm

Or contact us for further details: permissions@emeraldinsight.com 